\title{
O Papel do Professor na Construção Discursiva da Argumentação em Sala de Aula
}

\author{
Sylvia De Chiaro $^{1}$ \\ Selma Leitão ${ }^{2}$ \\ Universidade Federal de Pernambuco, Recife
}

\begin{abstract}
Resumo
A natureza canônica dos referentes do discurso de sala de aula, a relação assimétrica professor-aluno e a previsibilidade dos resultados das discussões parecem tornar a sala de aula um espaço pouco propício à argumentação. Entretanto, reconhecendo a importância desta como recurso didático, o presente artigo discute sua construção em situaç̧ões instrucionais. A tese central é que ações discursivas, nos planos pragmático, argumentativo e epistêmico, implementam a argumentação em sala de aula. Dois grupos de discussão da quinta série são analisados, um gerido pelos alunos e outro mediado pela professora. Os resultados mostram que ações facilitadoras da emergência e sustentação da argumentação surgem nos dois grupos, porém, ações que aproximam as conclusões dos alunos do conhecimento convencionalizado dependem prioritariamente da mediação da professora.

Palavras-chave: Argumentação; construção do conhecimento; mediação discursiva.
\end{abstract}

The Teacher's Role in the Discoursive Construction of the Argumentation in Classroom

\begin{abstract}
The representation of the topics discussed in classroom as being part of canonical knowledge, the asymmetric teacher/student relationship and the expectation of results stemming from discussion seem to make the classroom a place that is not very propitious to argumentation. Nonetheless, in recognition of the importance of using argumentation as a teaching resource, the present article discusses its construction in instructional situations. The central point is that discourse actions in a pragmatic, argumentative and epistemic realm implement argumentation in the classroom. Two fifth-grade discussion groups are analyzed, one generated by the students and the other mediated by the teacher. The results show that actions facilitating the emergence and sustaining of argumentation appear in both groups, but actions that bring the students' conclusions closer to conventional knowledge depend primarily on the mediation of the teacher.

Keywords: Argumentation; construction of knowledge; discourse mediation.
\end{abstract}

Este trabalho focaliza a argumentação como atividade social e discursiva que se realiza pela justificação de pontos de vista e consideração de perspectivas contrárias com o objetivo último de promover mudanças nas representações dos participantes sobre o tema discutido. Vista deste modo, a argumentação se caracteriza como uma discussão crítica (Van Eemeren \& Gootendorst, 1992) durante a qual pontos de vista são construídos, negociados e transformados.

O pressuposto central deste trabalho é que a ênfase sobre negociação e mudança - características definidoras da argumentação - confere a este tipo de discurso uma dimensão epistêmica que o institui como recurso privilegiado de mediação em processos de construção de conhecimento que ocorrem em contextos sociais diversos (Leitão, 1999, 2000b). Essa dimensão epistêmica remete à possibilidade - criada na argumentação de construção e transformação de crenças e conceitos e de implementação e desenvolvimento de raciocínios típicos do domínio do conhecimento a que tais crenças e conceitos se referem. Um segundo pressuposto, igualmente central neste

\footnotetext{
${ }^{1} \mathrm{O}$ estudo aqui reportado fez parte da dissertação de mestrado da primeira autora realizada sob orientação da segunda. As autoras agradecem ao $\mathrm{CNPq}$ pelo apoio concedido à realização desse trabalho na forma de bolsa de mestrado e de produtividade em pesquisa, respectivamente.

${ }^{2}$ Endereço para correspondência: UFPE, Pós-Graduação em Psicologia Cognitiva, $\mathrm{CFCH}, 8^{\circ}$ andar, Cidade Universitária. Recife, PE, 50670 901. Fone: (81) 21268272, Fax: (0xx81) 2126-1843.E-mail: selma_leitao2001@yahoo.com
}

trabalho, é oferecido pelo construto da mediação semiótica, tal como proposto por Vygotsky (2000) e elaborado por variados teóricos da chamada psicologia sócio-histórica (Wertsch, 1985; Wertsch, del Río \& Alvarez, 1995, entre outros). De acordo com esta perspectiva, formas superiores e tipicamente humanas de funcionamento psicológico se realizam e desenvolvem pela mediação de signos/ sistemas simbólicos, sobretudo da linguagem. Tais formas aparecem primeiramente embutidas em atividades sociais diversas do cotidiano da criança e, uma vez internalizadas, possibilitam sua constituição como sujeito de consciência e pensamento.

Partindo dos pressupostos acima, este trabalho examina o papel mediador da argumentação em processos que possibilitam a construção de conhecimento em uma situação social particular, a sala de aula. De modo mais específico, examina-se como ações discursivas dos participantes - da professora, em particular criam condições que possibilitam a emergência da argumentação em sala de aula e a instituem como método de negociação de diferenças de opinião que favorece a emergência de novas perspectivas sobre conteúdos curriculares.

\section{Argumentação e Construção de Conhecimento}

Em Leitão (1999, 2000b), a argumentação é descrita como uma atividade discursiva que potencializa mudanças nas concepções dos indivíduos sobre temas discutidos. $\mathrm{O}$ que confere à argumentação um potencial único neste sentido (e a distingue de outros tipos de discurso) é a forma como esta desencadeia, nos participantes, um processo 
de revisão de suas perspectivas a respeito do mundo, físico ou social. $O$ confronto entre a posição defendida pelo proponente de um argumento e dúvidas, pontos de vista alternativos e contra-argumentos, levantados por um oponente, impele o primeiro ao exame de suas posições à luz das perspectivas contrárias trazidas pelo segundo. Embora o engajamento de um indivíduo no processo de revisão de pontos de vista, por si só, não garanta mudanças de ponto de vista, este processo é visto como pré-requisito fundamental para que mudanças de perspectiva possam ocorrer (Leitão, 2000b). Partindo desta idéia, a autora propõe um procedimento analítico desenhado para capturar o processo pelo qual os indivíduos revêem suas posições no curso da argumentação. Este procedimento se ancora numa unidade de análise constituída por três elementos: argumento, contraargumento e resposta.

$\mathrm{O}$ argumento consiste num conjunto mínimo de ponto de vista e justificativa. Na unidade de análise proposta, este é o elemento que permite identificar a posição defendida por um falante e as idéias com as quais a justifica. $\mathrm{Na}$ argumentação cotidiana, é comum que um destes elementos permaneça implícito por conter informação já conhecida e/ou tacitamente aceita pelos participantes da argumentação (Van Eemeren \& Grootendorst, 1992). A noção de contra-argumento é definida num sentido lato que engloba qualquer idéia que desafia o ponto de vista do proponente de um argumento tornando-o menos aceitável aos olhos do oponente. Contra-argumentos tanto podem ser formulados por um interlocutor, presente na situação imediata em que a argumentação ocorre, como podem ser antecipados pelo próprio argumentador, caso em que se falaria da presença de um oponente imaginário na argumentação. Do ponto de vista analítico, o contra-argumento é o elemento que captura, nas falas dos participantes, vozes dos outros sociais (no sentido bakhtiniano do termo, descrito em Wertsch, 1991) que desafiam o ponto de vista do falante e trazem para a discussão um elemento de oposição indispensável para que a argumentação se institua no discurso (Freeman, 1991). Finalmente a resposta é definida como a reação imediata ou remota do falante a contraargumentos levantados. A identificação da reação do argumentador a perspectivas contrárias é vista aqui como um elemento crítico para a análise de processos de construção de conhecimento que têm lugar na argumentação. A comparação entre a formulação inicial de um argumento e a retomada deste após a emergência de contra-argumentos - ou seja, a resposta ao contra-argumento - é o recurso analítico que permite que se identifiquem eventuais mudanças na perspectiva inicial do argumentador.

O procedimento analítico que esta unidade de análise permite implementar parte da argumentação já instaurada e indaga do seu impacto sobre posições defendidas pelos participantes. Nada informa, porém - nem seria esperado que o fizesse - sobre as condições que permitem a implementação do discurso argumentativo em contextos sociais específicos. Refletir sobre estas condições é, entretanto, um ponto particularmente crítico quando se toma o procedimento acima como recurso para a análise da construção de conhecimento em sala de aula. A razão imediata para isso é que características específicas do discurso de sala de aula parecem dificultar a criação das condições consideradas indispensáveis à implementação de argumentação.

\section{Especificidade do Discurso de Sala de Aula}

O discurso de sala de aula tem já sido alvo de inúmeros estudos desenvolvidos nos campos da sociolingüística, antropologia, psicologia e educação. Rever os variados aspectos que estes estudos focalizam é algo que foge, entretanto, ao escopo deste trabalho (o leitor interessado encontrará em Mercer e Edwards (1987) e Coll e Edwards (1998) (boas introduções ao tema). O que se deseja focalizar aqui são algumas características deste discurso que, à primeira vista, poderiam restringir a possibilidade de surgimento de argumentação em contextos instrucionais (Leitão, 2000a, 2004).

Natureza Canônica dos Referentes do Discurso. Adeptos de variadas perspectivas teóricas concordam que a existência de polêmica e desacordo em torno de um tema é requisito primordial para que o discurso se torne argumentativo (Ex.: Coirier, Andriessen \& Chanquoy, 1999; Freeman, 1991; Stein \& Miller, 1993; Van Eemeren \& cols., 1996). Os tópicos sobre os quais se argumenta são questões abertas, não resolvidas, incertas e, portanto, sujeitas à discussão. Não havendo divergência em torno de um tema, desaparece a possibilidade do convencimento e torna-se sem sentido o argumentar. Diante disto, a relativa cristalização que caracteriza as perspectivas alvo da instrução de sala de aula parece, à primeira vista, contrastar com a natureza aberta dos tópicos sobre os quais se argumenta em situações não instrucionais. Os tópicos do discurso de sala de aula são, em sua maioria, parte do corpo de conhecimento socialmente legitimado e convencionalizado num dado domínio de conhecimento. Temas que remetem ao canônico não tendem a ser socialmente representados como polêmicos. Embora o grau em que temas curriculares são vistos como polemizáveis varie de um para outro tópico e de um para outro domínio do conhecimento (temas das ciências físicas, por exemplo, tenderiam a ser vistos como menos passíveis de polemização/argumentação do que interpretações de eventos históricas e sociais), uma característica comum a todos eles é que as definições e conceitos que constituem o conhecimento considerado canônico numa área não são passíveis de modificação a partir de discussões implementadas em sala de aula.

Assimetria nos Papéis dos Interlocutores. Enquanto método de negociação de divergências de pontos de vista, a argumentação pressupõe a possibilidade de mudança nas perspectivas adotadas por quaisquer dos participantes a respeito do tema discutido. Tais mudanças poderiam decorrer tanto da aceitação, por parte do proponente de um argumento, da plausibilidade da posição trazida por um oponente, como da elaboração - no curso mesmo da discussão - de uma terceira posição na qual aspectos dos pontos de vista inicialmente em confronto são integrados. Em um e outro caso, no entanto, a crença do proponente de que seu 
oponente, embora não aceitando inicialmente um certo ponto de vista, está preparado para aceitá-lo, constitui-se numa das condições preparatórias essenciais para que a argumentação se instale (Van Eemeren \& Grootendorst, 1992). Embora esta condição seja facilmente satisfeita na maioria das discussões sobre temas cotidianos, o mesmo não ocorre em grande parte das discussões que envolvem tópicos curriculares. A assimetria no que tange aos papéis dos interlocutores envolvidos nas discussões de sala de aula - professor e aluno - parece ser a responsável direta por esse estado de coisas. O professor, socialmente instituído como depositário e porta-voz de um conhecimento socialmente legitimado, não se coloca na posição de um interlocutor a ser convencido. A finalidade específica das discussões em que se engaja com os alunos é levá-los à aquisição de conceitos, formas de raciocínio e princípios considerados canônicos num certo domínio do conhecimento, não estando suas próprias perspectivas sobre os temas discutidos sujeitas a mudança em função da discussão com os alunos.

Pré-definição de Resultados. Uma característica típica da argumentação, vista como processo de negociação de diferenças de opiniões, é que o resultado deste processo permanece em aberto durante a discussão. Seu ponto de chegada é, em princípio, desconhecido. Expectativa bem diversa existe, no entanto, nas discussões sobre temas curriculares que ocorrem em situações instrucionais. Uma vez que os temas discutidos remetem a perspectivas compartilhadas e amplamente aceitas numa dada área de conhecimento (temas técnicos, científicos), o que é aceitável como conclusão final de uma discussão está, de antemão, definido pelos objetivos do professor, pelos currículos escolares e, em última instância, pelo conhecimento estabelecido na área. Conclusões idiossincráticas, caso surjam, tendem a ser silenciadas (Freitas, 1999).

Em suma, o que se poderia concluir a partir das considerações acima é que os tópicos curriculares, por serem relativamente definidos antes que sejam discutidos em sala de aula e por não serem estas definições passíveis de mudança a partir da discussão instalada, parecem não favorecer o desencadeamento de uma argumentação genuína em torno deles. Este estado de coisas tornaria os temas escolares menos sujeitos à argumentação quando comparados aos temas do cotidiano. Esta é de fato a tese defendida por Golder e Pouit (1999) num trabalho recente, em que as autoras analisam os variados graus de discutibilidade dos temas sobre os quais se argumenta. ${ }^{3}$

\section{A Discutibilidade de Tópicos Curriculares}

Como dito acima, os temas sobre os quais se argumenta admitem, tipicamente, múltiplas perspectivas. A percepção de uma idéia como discutível é, portanto, condição primeira para que se gere argumentação em torno dela. Golder e Pouit (1999) consideram passível de discussão o discurso no qual o locutor

\footnotetext{
${ }^{3}$ Os termos discutivel e discutibilidade serão usados neste trabalho para traduzir debatable e debatability, respectivamente.
}

apresenta argumentos baseados em valores compartilhados pelo interlocutor (o que torna tais argumentos potencialmente aceitáveis aos olhos deste) e usa recursos lingüísticos específicos que permitem apresentar o discurso como negociável. ${ }^{4}$ Como exemplo de discurso negociável, as autoras citam o "discurso 'natural' sobre assuntos do cotidiano (discurso de opinião) em contraste, por exemplo, ao discurso científico" (p. 137). O último, por ser relativamente 'cristalizado' e por não aceitar remodelações em função da argumentação de leigos, não seria facilmente percebido por estes como discutível.

Dentre os variados comentários que poderiam ser feitos sobre as idéias acima, dois, apresentados em Leitão (2004), são de particular interesse para o presente trabalho. O primeiro é que a forma como Golder e Pouit identificam discurso argumentativo e discurso de opinião parece compatibilizar a argumentação principalmente com o debate sobre temas controversos do cotidiano reduzindo substancialmente a possibilidade de se argumentar sobre, por exemplo, conceitos técnicos ou científicos. A impressão de quase exclusão destes últimos do âmbito dos temas potencialmente geradores de argumentação é reforçada pelo contraste claro que as autoras estabelecem entre discurso de opinião e discurso científico na citação acima.

Em segundo lugar, a forma como Golder e Pouit definem a discutibilidade do discurso revela uma espécie de tensão entre considerála uma representação dos debatedores sobre em que medida um tema é passível de discussão ou uma característica do próprio referente do discurso. Se, por um lado, as autoras afirmam ser "essencialmente a representação que o indivíduo tem do referente o que determina a construção do discurso" (p. 139) - o que, segundo Leitão (2000a; 2004), abre a possibilidade de que qualquer tema seja representado como discutivel - por outro, as autoras parecem situar a discutibilidade como um atributo do referente ao considerarem que temas técnicos e científicos, por estarem relativamente definidos antes de serem trazidos para discussões cotidianas, seriam menos discutíveis que temas cotidianos. A implicação imediata dessa última afirmação parece ser a redução da possibilidade de se gerar argumentação em situações instrucionais uma vez que os temas aí abordados fazem parte de conhecimento canônico. Essa idéia, no entanto, mostra-se dificilmente sustentável à luz de resultados da pesquisa emergente sobre a argumentação em situações instrucionais (Baker, 1999; Candela, 1998; Forman, Larreamendy-Joerns, Stein \& Brown, 1998; Leitão, 1999, 2000a, 2004; Orsolini \& Pontecorvo, 1992; Pontecorvo, 1987; Pontecorvo \& Girardet, 1993).

Leitão (2000a, 2004) considera que uma importante revisão deveria ser feita na noção de discutibilidade do discurso para que esta seja capaz de abarcar conceitualmente, o fenômeno, empiricamente demonstrável, de que argumentação pode ser

${ }^{4}$ Variados recursos lingüísticos, genericamente denominados marcadores de operações argumentativas de negociação, permitem que o discurso seja apresentado como negociável (Golder \& Coirier, 1994). Por ex., (1) indicadores de envolvimento do falante com os enunciados. Ao apresentar um ponto de vista como crença pessoal (Ex.: acho, creio, acredito que $\mathrm{X}$ ), o argumentador reconhece a existência de outras perspectivas sobre $\mathrm{o}$ mesmo tema, o que abre espaço, portanto, à negociação (Golder, 1992). (2) Expressões e moduladores de julgamento (talvez, certamente etc.) criam uma maior ou menor distância entre o falante e seu enunciado que permite ao interlocutor negociar o objeto do debate. (3) Presença de contra-argumentação, concessão e restrição. 
implementada em ambientes instrucionais. Essa revisão diz respeito ao locus no qual se situa a discutibilidade de um tema discursivo. Segundo a autora, a discutibilidade de um tema deveria ser vista, não como uma propriedade atribuída ao mesmo, mas como uma característica do discurso, que emerge na própria situação em que este é produzido. Nesta perspectiva, não só os argumentos sobre um tema, mas a própria discutibilidade deste tema é vista como um elemento de natureza social, discursivamente criado em situações comunicativas. Partindo-se dessa idéia se poderia dizer que qualquer tema poderia, em princípio, ser apresentado/representado como polêmico e, portanto, passível de discussão. A implementação da argumentação em sala de aula dependeria, pois, da possibilidade dos participantes criarem - no curso de suas interações verbais - uma representação dos temas curriculares como idéias passíveis de discussão.

Ainda segundo Leitão, a discutibilidade dos temas curriculares é criada pela implementação de ações discursivas específicas que podem ser descritas em três planos distintos: o pragmático, o argumentativo e o epistêmico (ver definições na seção seguinte). Tomando-se esse pressuposto como ponto de partida, o presente trabalho investigou empiricamente a emergência de argumentação em sala de aula através da análise de ações discursivas específicas que instituem a discutibilidade de temas curriculares.

\section{Método}

O episódio de argumentação analisado nesta seção foi produzido durante uma atividade regular de uma sala de aula de História com alunos da quinta série do ensino fundamental de uma escola privada de nível sócio-econômico médio. Na oportunidade em que a atividade de sala de aula foi registrada, essa instituição passava pela implantação do Programa Filosofia para Crianças proposto por Mathew Lipman (Lipman, Sharp \& Oscanyan, 1980), cujo objetivo principal é desenvolver uma educação voltada para o pensar, a partir da iniciação dos alunos à discussão filosófica de temas cotidianos. Um pressuposto básico desta proposta é que trocando idéias entre si, os alunos internalizam processos de diálogo, se tornam mais reflexivos e começam a exercitar o pensar por si mesmos. Na implementação do programa, os professores receberam treinamento específico para habilitá-los a trabalhar conteúdos de quaisquer disciplinas a partir da perspectiva proposta por esse programa. A escolha dessa escola como alvo para o presente estudo ocorreu devido à suposição de que, estando a mesma engajada em uma proposta educacional fundamentada em discussão e reflexão, se constituiria em um terreno fértil para a observação da argumentação em sala de aula.

A atividade na qual os alunos trabalhavam na ocasião, elaborada por Rodrigues (2001) em acordo com a professora de História, focalizava o tema escravidão. Nessa atividade, solicitou-se aos alunos que, reunidos em dois subgrupos, discutissem algumas questões apresentadas a respeito de um fragmento de texto retirado do próprio livro didático adotado pela escola de modo a que chegassem a uma perspectiva compartilhada sobre as mesmas. Em um desses subgrupos a discussão foi mediada pela professora enquanto no outro coube às próprias crianças a condução da discussão. A professora responsável pela implementação da atividade em sala de aula não recebeu nenhum tipo de treinamento ou instrução a respeito de como proceder durante a atividade e a pesquisadora, embora presente às discussões geradas nos dois grupos, não interferiu diretamente nas mesmas. As discussões foram integralmente videogravadas. No transcrito analisado abaixo foram usadas as seguintes convenções: ( ) para falas inaudíveis, / para falas interrompidas, [...] para pausas, (MAIÚSCULAS EM PARÊNTESES) para comentários do analista e MAIÚSCULAS para ênfase ou acento forte. Para proteger a identidade dos participantes, seus nomes foram substituídos.

Critérios de Análise: As Marcas da Discutibilidade. Como dito anteriormente, o foco da presente análise incide sobre as ações discursivas dos participantes as quais estabelecem a discutibilidade dos temas curriculares e, ao fazê-lo, contribuem para instituire manter a argumentação na sala de aula. A análise focaliza ações executadas em três planos: $\mathrm{o}$ pragmático, o argumentativo e o epistêmico (Leitão, 2000a, 2004).

No plano pragmático, procurou-se identificar em que medida as ações verbais dos participantes criavam em sala de aula condições consideradas cruciais para que o discurso se tornasse argumentativo. $\mathrm{Ou}$ seja, em que medida tais ações apresentavam o tema como passível de discussão (polêmico), legitimavam a divergência a respeito do tema em pauta, instituíam a argumentação como método para a resolução de divergências existentes e estabeleciam o consenso como meta na discussão. A análise no plano argumentativo focalizou a forma como os participantes implementavam (ou estimulavam outros a implementar) operações definidoras da argumentação: definição/justificação de pontos de vista e negociação de divergências. Como indicado anteriormente, a negociação de diferenças de pontos de vista éimplementada no discurso predominantemente por ações verbais que remetam ao exame de contraargumentos e à elaboração de resposta a estes. Finalmente, no plano epistêmico procurou-se capturarações verbais com as quais os participantes traziam para a discussão informações (conceitos, definições etc.) consideradas relevantes ao domínio do conhecimento em questão, implementavam procedimentos emodos de raciocínio típicos do campo de conhecimento em pauta (Pontecorvo, 1987) e conferiam estatuto epistêmico às conclusões estabelecidas. A identificação de ações verbais nos três planos descritos acima exige uma apreensão do sentido das falas dos participantes que é eminentemente interpretativa. Para tanto, a análise desenvolvida se beneficiou de insights e métodos oferecidos pelas perspectivas de análise do discurso e da conversação (Potter\& Wetherell, 1987; Van Rees, 1992).

Argumentação Mediada pela Professora. O fragmento de protocolo analisado a seguir foi gerado durante a discussão de um enunciado apresentado às crianças pela professora. Após a leitura de um trecho de um livro didático que abordava a escravidão, a professora solicitou aos alunos que se posicionassem em relação à seguinte afirmação: "percebese" (no trecho lido) "que se procurou justificar a escravidão do período colonial em face das necessidades de acumulação capitalista da época". Caso discordassem da afirmação, os alunos deveriam oferecer justificativas alternativas para a escravidão. Embora fosse esta a questão proposta, não é exatamente em relação a ela que a discussão se estabelece. $\mathrm{O}$ 
que se torna alvo de discussão é a compreensão de alguns alunos a respeito do posicionamento de um dos colegas, Luís, sobre as diferenças, socialmente criadas, entre brancos e negros.

Nos momentos que antecederam a produção do fragmento em questão, José entendera a posição de Luís a respeito da diferença brancos / negros como algo que estaria vinculado à questão econômica. Palavras de José: "(Luís disse que) o negro não pode ser rico, eu entendi assim, eu juro a você que eu entendi assim, que o negro nunca podia ser rico". Vânia, discordando, defendera a idéia de que a questão deveria ser concebida em termos de diferenças em "modos de pensar": "É porque ele (LUÍS) disse que os negros são diferentes porque é a mesma ( ) mas a gente não tá falando de diferença assim se um tem mais grana, ou tem ( ) pequeno, a gente tá falando das ( ) é das, das diferenças sociais e econômicas, ou seja, é, você (REFERINDO-SE A LUÍS) quis transmi, você quis transmitir assim que eles não são iguais, eles são diferentes porque pensam diferente, ninguém pensa igual, ninguém, então el, eles não podem ter [...] CULTURAS e modos iguais, entendeu?’. Neste ponto, a discussão continua com o pedido da professora de posicionamento de outra aluna, Silvana.

(T413) Profa.: Silvana, o que é que você acha dessa questão que surgiu aí?

Plano Pragmático: A pergunta da professora estimula uma participante do grupo a entrar na discussão, desafiando-a a examinar os pontos de vista já apresentados, atribuindo-lhe, portanto, o papel de interlocutora crítica a respeito do assunto. Além disso, sua pergunta institui o debate como método para a resolução das diferenças surgidas, legitima a possibilidade de discordância e apresenta o tema como polêmico.

Plano Argumentativo: A professora estimula a formulação de um ponto de vista da parte de Silvana e, pelo fato de sua pergunta aparecer de forma aberta, abre espaço para o surgimento de um ponto de vista alternativo ao já proposto na discussão.

(T414) Silvana: É, é que, como Vânia disse, né? Que um não pensa igual ao outro por isso o que Luís disse eu também discordo porque claro que eles têm culturas diferentes porque um não é, não tem o pensamento do outro, então, exemplo, eu não tenho o pensamento de Rose, pode ela pode pensar uma coisa e eu não posso pensar/

Plano Argumentativo: Com sua resposta à pergunta da professora, Silvana se alinha à posição, defendida por Vânia, de que brancos e negros diferem quanto a modos de pensar, e justifica seu ponto de vista fazendo apelo a um exemplo extraído da própria experiência.

Plano Epistêmico: Do ponto de vista do tema discutido, Silvana inicia aqui um processo de conceituação da natureza das diferenças em questão. Além disso, Esse novo elemento, trazido pelas alunas, diferenças de pensamento, acabará por se converter em premissa do novo argumento de Luís (ver T418).

(T415) Profa.: E é o dinheiro, o poder, a riqueza que vai medir as diferenças culturais?

Plano Pragmático: Com essa pergunta, a professora legitima a diferença de pontos de vista surgida: de um lado, são colocados Luís e José, preocupados em vincular a diferença entre negros e brancos à questão econômica e, de outro, Vânia e Silvana que trazem um novo elemento diferenciador entre negros e brancos - as diferenças de pensamento.

Plano Argumentativo: A pergunta acima, traz um ponto de vista implícito da professora, "dinheiro, poder e riqueza" (os aspectos econômicos em questão nessa discussão) "não medem" (ou seja, não estabelecem) "diferenças culturais". Além disso, nota-se que esse ponto de vista é contrário ao posicionamento de Luís e José. Neste sentido, ela levanta dúvida sobre o critério econômico como base das diferenças culturais e ainda estimula os alunos a posicionarem-se, instaurando, portanto, uma argumentação sobre a divergência surgida. A dúvida deixa implícita a possibilidade de defesa de um ponto de vista contrário.

Plano Epistêmico: A pergunta da professora prioriza as diferenças culturais sobre as econômicas, perspectiva defendida por Silvana e Vânia. Sua ação confere, portanto, estatuto epistêmico ao ponto de vista de Silvana e Vânia. Essa legitimação se tornará ainda mais clara nos turnos 419-421. Ainda no plano epistêmico, nota-se que a fala da professora focaliza o conceito de diferença cultural. A definição do significado de palavras ou expressões é considerada, dentro das categorias utilizadas por Pontecorvo e Girardet (1993), como uma operação epistêmica típica (embora não exclusiva) do domínio da História.

(T416) Silvana: Não, não porque/

Plano Argumentativo: Apesar de ter sido interrompida na justificativa, o ponto de vista de Silvana aparece aqui em concordância com o da professora, implícito em T415.

(T417) Profa.: CULTURAIS ?

(T418) Luís: Não, cada um pensa como pode também, né?

Plano Argumentativo: A resposta de Luís marca sua aceitação do ponto de vista, implícito na pergunta da professora em T415. Luís e Silvana (T110) acabam concordando, portanto, que a questão toda girava em torno das diferenças culturais e que estas dizem respeito mais a modos de pensar do que a fatores econômicos.

Plano Epistêmico: Do ponto de vista do campo conceitual focalizado na discussão (diferenças entre negros e brancos, diferenças culturais vs. econômicas), a fala de Luís marca uma primeira diferenciação entre critérios econômicos e culturais.

(T419) Profa.: Então vamos dizer que Luís não soube, né

(T420) Silvana: Explicar

(T421) Profa.: Explicar as idéias.

Plano Epistêmico: Ao mostrar que Luís não estava sabendo "explicar as idéias", a professora confere estatuto epistêmico à conclusão, co-construída por ela e pelos alunos, de que as diferenças entre negros e brancos situam-se na ordem do cultural - são diferenças entre "modos de pensar".

(T422) Luís: Tem o lado do índio tam, o ou, o, o índio, um exemplo, o índio ele, os índios eles eram livres, eles, como é o nome? Eles andam livres, sem roupas assim, seminus, e os brancos eles andam de roupas, como a gente aqui, ta, de tênis, short, camisa, meia, lá eles vivem descalças/

Plano Epistêmico: A fala de Luís expande o conceito de diferenças culturais agregando novos aspectos que podem ser aí categorizados. A interpretação de que embutido nessa fala há um processo de categorização é legitimada pela reação da professora em T424 abaixo.

Psicologia: Reflexão e Crítica, 2005, 18(3), pp.350-357 
(T423) José: Mas, mas não é só/

(T424) Profa.: Isso aí são diferenças o quê?

(T425) Luís: Culturais, então?

Plano Epistêmico: Percebendo que o conceito de diferenças culturais continua em construção, a professora enfatiza mais um modelo de raciocínio (forma de argumentação) típico (embora não exclusivo) do campo de conhecimento enfocado, qual seja, argumentação baseada em categorizações. Ou seja, a operação epistêmica em andamento refere-se à tentativa de definir algo como membro de uma classe.

(T426) José: E não é só por causa disso que o, [...] vai ser, o índio, né?

(T427) Profa.: É, o índio.

(T428) José: O índio vai ser pi, pior do que o branco só porque/...

(T429) Silvana: Porque se todo mundo tivesse a mesma cultura.../

(T430) Luís: Todo mundo não é melhor que o outro, todo mundo é do mesmo jeito, agora cada um tem a sua cultura.

(T431) Silvana: Mas se tivesse a mesma cultura, como é que ia ser? ( ) todo mundo pelado por aqui.

Plano Argumentativo: Tomadas em conjunto, as falas de José (T426, 428), Silvana (T429, T431) e Luís (T430) introduzem na discussão um novo ponto de vista: a igualdade (o valor humano?) dos culturalmente diferentes.

(T432) Profa.: Ninguém po, pode ser porque as pessoas trabalham, vivem, vivem de modos diferentes.

Plano Argumentativo: Neste turno de fala a professora formula um argumento aproveitando as informações trazidas pelos próprios alunos, embora não fique de todo explícito que ponto de vista ela tenta estabelecer - o quê "ninguém pode ser".

Plano Epistêmico: Além disso, a fala da professora retoma as contribuições dos alunos dentro de uma formulação mais elaborada do conceito de diferença cultural. Ao ratificar as contribuições dos alunos, ela confere estatuto epistêmico às conclusões por eles formuladas.

(T433) Luís: É a diferença de luta para os europeus e de luta para $[\ldots]$

(T434) Tadeu: De guerra

(T435) Luís: De guerra, esses negócios.

(T436) Profa.: Para os índios e guerra para os europeus. Alguém quer colocar aqui? Pedro? Fazer mais alguma colocação?

Plano Pragmático: Ao checar a possibilidade de mais alguma contribuição existir sobre o assunto, a professora mantém aberta a possibilidade de que a argumentação se desenvolva, seja pela ação de um participante inespecífico (alguém) ou do aluno que ela seleciona como próximo falante (Pedro).

(T437) José: Vê, agora ele (LUÍS) falou tudo bem, agora ele falou que só/

(T438) Profa.: Agora ele organizou as idéias.

(T439) José: Organizou, mas naquela hora ele falou que não ia dar certo o negro viver com o branco porque eram diferentes as, as culturas e agora ele já falou diferente, ele mudou, mudou/
(T440) Profa.: Ele já mudou a opinião dele/

(T441) José: É.

As falas finais do fragmento acima parecem selar um acordo entre a professora e os alunos (na voz de José) quanto à ocorrência de mudança na perspectiva inicial de Luís sobre a natureza das diferenças, socialmente estabelecidas, entre negros e brancos. Mesmo que a professora talvez tivesse já compreendido que questões culturais permeavam as falas de Luís, nem ele nem o grupo pareciam ter inicialmente essa compreensão. Isso provavelmente se devia ao fato do conceito de diferença cultural não estar bem elaborado inicialmente, nem para ele nem para o grupo como um todo. Embora não se possa, naturalmente, afirmar que esse conceito esteja agora completamente estabelecido no entendimento de Luís, pode-se, entretanto, perceber uma mudança no seu entendimento - uma flexibilização de sua posição inicial - diante da argumentação gerada.

Argumentação entre Pares (Grupo não Mediado pela Professora). O fragmento analisado nesta seção registra uma discussão entre alunos quanto à concordância, ou não, com a afirmação extraída do livro texto adotado na disciplina em curso: "A violentação da dignidade do trabalho foi e é uma constante do desenvolvimento econômico do Brasil"' (Medeiros, 1999, p. 121). Momentos antes da primeira fala transcrita abaixo ser produzida, Rogério havia concordado com essa afirmação justificando que "todo dia pode ser visto na televisão o desrespeito aos trabalhadores e as crianças menores de idade trabalhando".

(T45) Sandra: Quem discorda de... desse menino aî (APONTANDO PARA ROGÉRIO)

Plano Pragmático: A pergunta de Sandra convida os colegas a examinarem o ponto de vista de Rogério, criando inclusive a possibilidade de discordância em relação ao mesmo. Neste sentido, pode-se afirmar que sua fala apresenta o referente do discurso passível de discussão.

Plano Argumentativo: No plano argumentativo, a pergunta estimula a formulação de pontos de vista alternativos e/ou objeções à posição de Rogério.

(T46) Sandra: Vai! (APONTANDO PARA FELIPE QUE LEVANTARA O BRAÇO)

(T47) Rogério: Esse menino aí tem nome.

(T48) Sandra: Sim, Rogério. Por que você (APONTANDO PARA FELIPE) discorda? Por que você discorda de Rogério?

(T49) Felipe: Sei lá... você tava perguntando quem discordava..

(T50) Lucas: Ah Meu Deus..

(T51) Sandra: Então responde porque você discorda.

Plano Argumentativo: Em T46, T48 e T51 Sandra estimula Felipe a elaborar sua discordância em relação ao argumento de Rogério, insistindo que o primeiro defenda o posicionamento assumido. A fala de Sandra, mais uma vez, estimula a implementação de operações definidoras da argumentação (contra-argumentação, justificação).

(FELIPE FAZ SINAL DE QUE NÃO SABE)

(T52) Lucas: Por que você (FELIPE) discorda, inteligência rara? 
Plano Argumentativo: Lucas repete a pergunta de Sandra, requerendo de Felipe a justificação de sua posição contrária ao ponto de vista de Rogério (contra-argumentação). O tom de voz (recurso supra-segmental descrito em Marcuschi, 1999) e o conteúdo irônico com que se refere ao colega informam, entretanto, que sua fala não apenas estimula a implementação de uma operação típica da argumentação, mas, também critica o mesmo por tomar uma posição sem saber defendê-la.

(T53) Sandra: Ele (ROGÉRIO) falou um negócio que eu acho que está certo. Isso aí acontece muito no Brasil/

(T54) Rogério: Todo dia a gente vê.

(T55) Sandra: Isso aí acontece no Brasil/

Plano Argumentativo: Em T53 e T55 Sandra adere ao ponto de vista de Rogério, repetido em T54. A repetição é vista como recurso argumentativo que usualmente favorece a aceitação do um argumento. Costuma-se chamar essa técnica "de 'técnica da água mole em pedra dura'. Usamos a repetição como meio de 'martelar' na cabeça do interlocutor até que este aceite os argumentos propostos" (Koch, 2000, p. 104).

(VÁRIOS ALUNOS FALAM AO MESMO TEMPO)

(T56) Sandra: Psiu!!! (AS FALAS SUPERPOSTAS CONTINUAM)

(T57) Sandra: Gente! Quem quer falar levanta a mão, é melhor... (ROGÉRIO LEVANTA A MÃO) Fala Rogério.

(T58) Rogério: ... o que eu quero falar é que a gente vê muito, né? Todo dia tem nos jornais, passa na televisão, até em jornal que a gente lê assim/

(VÁRIOS ALUNOS CONTINUAM A FALAR AO MESMO TEMPO)

(T59) Sandra: E essa violência/

(T60) Rogério: ... a maioria das vezes é sobre violência no Brasil.

Plano Argumentativo: Em T58 e T60, Rogério amplia a justificativa que apresentara anteriormente. Se antes ele defendia o ponto de vista de que existe violentação da dignidade do trabalho no Brasil com base no que é mostrado todo dia na televisão, agora ele amplia seu apelo à autoridade dos meios de comunicação incluindo os jornais.

Plano Epistêmico: O apelo de Rogério à credibilidade dos veículos de comunicação de massa ilustra uma forma de raciocínio comum à área de conhecimento focalizada. Segundo Pontecorvo e Girardet (1993), o apelo se caracteriza como uma ação de defesa de um ponto de vista através de algo relevante para o assunto em questão (neste caso, a credibilidade dos meios de comunicação). Rogério justifica a pertinência de seu ponto de vista a partir das informações trazidas por meios de comunicação, realizando assim um importante procedimento que encontra paralelos na atividade histórica interpretativa.

\section{Discussão e Conclusões}

O propósito deste estudo foi investigar a construção discursiva da argumentação enquanto recurso didático numa aula de História. A mediação da professora foi vista como um importante fator a ser considerado em termos da emergência da argumentação neste contexto. A análise proposta buscou observar se e de que maneira suas ações verbais favoreciam a emergência e manutenção da argumentação enquanto recurso de mediação na construção do conhecimento. A análise apresentada acima permite observar que a argumentação com e a sem mediação da professora apresentam similaridades e diferenças relevantes para uma reflexão sobre o potencial mediador deste tipo de discurso na construção do conhecimento.

Em termos da ocorrência de ações no plano pragmático, os resultados mostram similaridades entre os dois grupos. Embora no grupo mediado pela professora se verifique maior variedade de ações verbais que apresentam o tema focalizado como passível de discussão e, dessa forma, possibilitam o surgimento de argumentação, também no grupo gerido apenas pelos alunos essas ações foram observadas. Em ambos os grupos, as falas produzidas por professora (T413, T436) e alunos (T45) estabelecem as condições cruciais para que o discurso dos participantes se tornasse argumentativo.

Similaridades também foram encontradas nas ações analisadas no plano argumentativo. Em ambos os grupos, argumentos e contra-argumentos foram formulados (Ex.: T415 e T432 no grupo mediado pela professora e em T55 e T60 no grupo gerido pelos alunos) bem como estímulos à implementação dessas operações definidoras da argumentação puderam ser observados (T413, grupo com professora e T45, T51, T52 no grupo sem a presença da mesma).

Dos três planos propostos por Leitão (2000a, 2004) e analisados neste estudo, foi no plano epistêmico que pôde ser observada a diferença mais importante entre os dois grupos no que diz respeito ao papel da argumentação como recurso mediador na construção do conhecimento. Ações no plano epistêmico são aquelas que aproximam as falas do aluno não só de conteúdos, mas também de formas de raciocínio próprias do campo de conhecimento enfocado. $\mathrm{Na}$ análise do primeiro fragmento acima se vêem várias ocasiões em que a professora oferece modelos de raciocínios típicos do domínio da História (T415, T424) e confere estatuto epistêmico a conclusões estabelecidas pelas crianças (T425, T421, T432). No entanto, algo diverso observa-se no grupo em que ela não está presente. Apesar do oferecimento de informações (T414) e, principalmente, de modelos de raciocínio (T418, T422, T60) ter sido observado também entre os alunos, em nenhum momento foi possível observar algum dos alunos conferindo estatuto epistêmico a uma conclusão estabelecida entre eles.

Esse resultado não é de se surpreender uma vez considerados dois aspectos importantes e definidores da situação social em que a argumentação analisada se instalou. Primeiro, estando os alunos engajados num processo de construção do conhecimento, torna-se menos provável que percebam a si mesmos (e aos colegas) como estando em posição de legitimar uma conclusão estabelecida por algum dos participantes sobre o assunto em discussão. Segundo, é da professora, enquanto participante socialmente instituída como representante desse saber a ser construído pelos alunos, que se espera o exercício desse papel 
crucial. Embora os alunos consigam, mesmo sem a presença da professora, se aproximar de formas de raciocínio típicas da História, as discussões e conclusões estabelecidas entre eles permaneceriam no nível da mera troca de opiniões, caso não houvesse uma ação que as legitimasse e aproximasse do conhecimento pretendido. Assim, a partir da utilização de expressões típicas de aprovação (Ex.: certo), ou a partir da reconstrução das falas dos alunos (Ex.: em T432), a professora, diferentemente dos alunos, em vários momentos pôde estabelecer a aceitabilidade de conclusões estabelecidas por eles, aproximando-as assim do conhecimento canônico no domínio da História.

Os resultados de uma forma geral sugerem, portanto, que, embora a argumentação em ambos os grupos possibilite reflexão, discussão e construção de novos sentidos, o processo social de apropriação do conteúdo curricular depende significativamente da mediação do professor na medida em que suas ações discursivas conferem estatuto epistêmico ao discurso dos alunos. A despeito da participação ativa na construção de seus próprios processos de aprendizagem, não se pode assumir que eles possam recriar, através de suas atividades e experiências, um conhecimento culturalmente produzido. É necessário que um processo social e comunicativo de apropriação de um conteúdo preexistente aconteça e para isso, o papel do professor - ou de agentes outros socialmente investidos na função de representantes do saber convencionalizado a ser aprendido pelos alunos - torna-se fundamental.

\section{Referências}

Baker, M. (1999). Argumentation and constructive interaction. Em G. Rijlaarsdam \&E. Espéret (Orgs.), Studies in writing: Foundations of Argumentative text processing (Vol. 5, pp. 179-202). Amsterdã: Amsterdam University Press.

Candela, A. (1998). A construção discursiva de contextos argumentativos no ensino de ciências (B. A. Neves, Trad.). Em C. Coll \& D. Edwards (Orgs.), Ensino, aprendizagem e discurso em sala de aula: aproximacões ao estudo do discurso educacional (pp. 143-169). Porto Alegre: ArtMed.

Coll, C. \& Edwards, D. (1998). Ensino, aprendizagem e discurso em sala de aula: aproximaçöes ao estudo do discurso educacional (B. A. Neves, Trad.). Porto Alegre: ArtMed.

Coirier, P., Andriessen, J. \& Chanquoy, L. (1999). Em G. Rijlaarsdam \& E. Espéret (Orgs.), Studies in uriting: Vol. 5 Foundations of Argumentative text processing (pp. 1-28). Amsterdã: Amsterdam University Press.

Forman, E. A., Larreamendy-Joerns, J., Stein, M. K. \& Brown, C. A. (1998). 'You're going to want to find out which and prove it': Collective argumentation in a mathematics classroom. Learning and Instruction, 6, 527-548.

Freeman, J. B (1991). Dialectics and the macrostructure of arguments. Berlin: Foris.

Freitas, A. F. (1999). O diálogo em sala de aula. Curitiba: HD.

Golder, C. (1992). Production of elaborated argumentative discourse: The role of cooperativeness. European Journal of Psychology of Education, 7, 51-59.

Golder, C. \& Coirier, P. (1994). Argumentative text writing: Developmental Trends. Discourse Processes, $18,187-210$
Golder, C. \& Pouit, D. (1999). For a debate to take place the topic must be debatable. Developmental evolution of the negotiation and debatibility of arguments. Em G. Rijlaarsdam \& E. Espéret (Orgs.), Studies in writing: Foundations of Argumentative text processing (Vol. 5, pp. 137-148). Amsterdã: Amsterdam University Press.

Koch, I. V. (2000). A inter-ação pela linguagem. São Paulo: Contexto.

Leitão, S. (1999). Contribuições dos estudos contemporâneos da argumentação a uma análise psicológica de processos de construção de conhecimento em sala de aula. Arquivos Brasileinos de Psicologia, 1, 91-109.

Leitão, S. (2000a, Outubro). A construção discursiva da aryumentação em sala de aula. Trabalho apresentado na XXX Reunião Anual da Sociedade Brasileira de Psicologia, Brasília.

Leitão, S. (2000b). The potential of argument in knowledge building. Human Development, 43,332-360.

Leitão, S. (2004). Arguing and learning. (não-publicado)

Lipman, M., Sharp, A. M. \& Oscanyan, F. S. (1980). Philosoply in the classroom. Pliladelphia: Temple University Press.

Marchuschi, L. A. (1999). Análise da conversação. São Paulo: Ática.

Medeiros, D. H. de (1999). História \& Interação. Curitiba: Módulo.

Mercer, N. \& Edwards, D. (1987). Common knowledge. The development of understanding in the classroom. London: Routledge.

Orsolini, M. \& Pontecorvo, C. (1992). Children's talk in classroom discussions. Cognition and Instruction, 9, 113-136.

Pontecorvo, C. (1987). Discussing for reasoning: The role of argument in knowledge construction. Em E. de Corte, H. Lodewijks, R. Parmentier \& P. Span (Orgs.), Learning and instruction: A publication of the European Association for Research on Learning and Instruction.(pp.239-250). Oxford, England/Leuven, Belgium: Leuven University Press.

Pontecorvo, C. \& Girardet, H. (1993). Arguing and reasoning in understanding historical topics. Cognition and Instruction, 11, 365-395.

Potter, J. \& Wetherell, M. (1987). Discourse and social psychology. London: Sage

Rodrigues, S. R. De C. R. (2001). A emeryência da argumentação como recurso mediador na construção de conbecimentos em uma sala de aula de história. Dissertação de mestrado não publicada, Curso de Pós-Graduação em Psicologia, Universidade Federal de Pernambuco. Recife, PE.

Stein, N. \& Miller, C. (1993). The development of memory and reasoning skill in argumentative contexts: Evaluating, explaining, and generating evidence. Em R Glaser(Org.), Advances in instructional psychology (pp. 286-335). Hillsdale, NJ: Erlbaum.

Van Eemeren, F. H. \& Grootendorst, R. (1992). Argumentation, communication, and fallacies: A pragma-dialectical perspective. Hillsdale, NJ: Lawrence Erlbaum.

Van Eemeren, F. H., Grootendorst, R., Henkemans, F. S., Blair, J. A., Jonhson, R. H., Krabbe, E. C. W., Plantin, C., Walton, D. N., Willard, C. A., Woods, J., Zarefsky, D. 1996). Fundamentals of argumentation theory: A bandbook of bistorical backgrounds and contemporary developments. Mahwah, NJ: Erlbaum.

Van Rees, M. A. (1992). The use of language in conversation. Amsterdã: Sic Sat.

Vygotsky, L. S. (2000). Pensamento e linguagem. São Paulo: Martins Fontes.

Wertsch, J. V. (1985). Vygotsky and the social formation of mind. Cambridge, MA: Harvard University Press.

Wertsch, J. V. (1991). Voices of the mind. Cambridge, MA: Harvard University Press.

Wertsch, J. V., del Río, P. \& Alvarez, A. (1991). Sociocultural studies of mind. Cambridge, UK: Cambridge University Press.

Recebido: 19/03/2004

$1^{a}$ revisão: $24 / 08 / 2004$

Aceite final: $22 / 10 / 2004$

Sobre as autoras

Sylvia de Chiaro é Doutoranda e Mestre em Psicologia pela Universidade Federal de Pernambuco.

Selma Leitão é Doutora em Psicologia pela University of Cambridge, Inglaterra. É Professora da Pós-Graduação em Psicologia da Universidade Federal de Pernambuco e pesquisadora apoiada pelo CNPq. 